\title{
Arbuscular mycorrhiza-like biotechnological potential of Piriformospora indica, which promotes the growth of Adhatoda vasica Nees
}

\author{
Mahendra Rai* \\ Department of Biotechnology \\ Amravati University \\ Amravati-444602, Maharashtra, India \\ Tel: $917212662207 / 8$; ext. 267 \\ Fax: $917212660649 / 2662135$ \\ E-mail: mkrai123@rediffmail.com \\ pmkrai@hotmail.com \\ Ajit Varma \\ Amity Institute of Herbal and Microbial Studies \\ Sector 125, New Super Express Highway, \\ NOIDA, India \\ Tel: 951202432400 \\ Fax: 951202432200 \\ E-mail: ajitvarma@aihmr.amity.edu \\ ajitvarma73@hotmail.com
}

Keywords: Adhatoda vasica, arbuscular mycorrhiza-like,biotechnological potential, growth promotion, Piriformospora indica.

We report the growth promoting potential of Piriformospora indica, which is a newly discovered arbuscular mycorrhiza-like fungus. It is a facultative symbiont and unlike arbuscular mycorrhizal fungi, it can be cultured in vitro. Adhatoda vasica is a medicinal plant. Rapid proliferation of roots was recorded in $A$. vasica withan important root colonization estimated to 95\% after 6 months. $P$. indica improved growth of $A$. vasica. This association forms a new host-symbiont combination.

Piriformospora indica, a new plant growth promoter was discovered by Verma et al. (1998). The fungus is a member of Basidiomycotina. It is characterized by the formation of typical pyriform chlamydospores. A perusal of current literature has shown that $P$. indica has enormous potential for growth promotion of plants by colonization of roots (Franken et al. 1998; Blechert et al. 1999; Varma et al. 1999; Singh et al.2000; Rai et al. 2001; Malla et al. 2002, Rai and Varma, 2002). P. indica is similar to arbuscular mycorrhizal fungi in many respects (Varma et al. 1999; Singh et al. 2000; Varma et al. 2001). But, unlike arbuscular mycorrhizal fungi, it can be cultured in artificial medium. Initially, the growth promotion studies were carried out on Zea mays, Nicotiana tabaccum, Glycine max, Pisum satium, etc. Later, the fungus was assessed for its growth stimulation in timber-yielding and medicinal plants.
Rai et al. (2001) reported growth increase in Withania somnifera and Spilanthes calva.

Adhatoda vasica Nees (Common name-Malabar nut; Family-Acanthaceae) is an evergreen shrub. It is well known for preparation of medicine for bronchitis, asthma and other pulmonary infections. Glycodin ${ }^{\circledR}$, a famous product used for the cure of bronchitis is extracted from the leaves of this plant. It is also known for its anti-artritis, antiseptic, antimicrobial, expectorant, sedative and antituberculosis properties (Dey, 1980; Singh and Jain, 1987). In Ayurveda, several medicines are manufactured by this plant. Due to increasing demand of $A$. vasica by pharmacies there is a need of its rapid multiplication.

In the present study, cuttings of $A$. vasica were inoculated with $P$. indica to assess the growth promoting property of $P$. indica on this important medicinal plant.

\section{MATERIALS AND METHODS}

\section{Mycobiont}

The fungus was maintained on Kafer's medium (Kafer, 1977). The culture medium was inoculated with agar containing fungal discs and incubated at $30 \pm 2^{\circ} \mathrm{C}$ under constant shaking conditions (100 rpm) in dark for 10 days.

*Corresponding author 
Fungal mycelium was harvested and washed several times with sterile water (Figure $1 \mathrm{a}$ and $1 \mathrm{~b}$ ) and thereafter inoculated into the roots present in glass bottles containing the cuttings of $A$. vasica.

\section{Photobionts}

Fresh cuttings of healthy plants of A. vasica were selected at Danielson College garden of Chhindwara, Central India. These cuttings $(6 \mathrm{~cm}$ long) were initially sterilized with $0.1 \% \mathrm{HgCl}_{2}$ for $5 \mathrm{~min}$ and kept in transparent glass bottles containing sterilized water in order to initiate formation of adventitious roots (Figure 1c). Inoculum of homogenized mycelium of $P$. indica $(5 \mathrm{~g})$ prepared as below was mixed in the water of the bottles The plants were grown at normal room temperature $\left(22 \pm 2^{\circ} \mathrm{C}\right)$ normal day light for 10 days.

\section{Pot-experiment}

The pot culture was composed of a mixture of soil: sand: farm-yard-manure $(3: 1: 1)$. This mixture was autoclaved 3 times for 3-consecutive days at the interval of $12 \mathrm{hrs}$. The cuttings with pre-inoculated roots were then transferred to the pots and grown in natural environmental conditions.

\section{Parameters and staining of root-samples}

The parameters measured in the present study were the height of the stem and the percentage of root colonization in inoculated and uninoculated plants after 2, 3, 4, 5 and 6 months of growth in the pots. The fresh and dry weights of A. vasica were measured after 6 months.

The roots were stained following the method suggested by Phillip and Hayman (1970). Fine feeder roots of $A$. vasica were washed thoroughly in running tap water and cut into 1 $\mathrm{cm}$ pieces. They were subsequently treated with $10 \% \mathrm{KOH}$ solution overnight. Thereafter, the root-pieces were washed 3-5 times with sterilized distilled water and treated with $1 \%$ $\mathrm{HCl}$ for 3-4 min. The root-pieces, were finally stained with $0.05 \%$ trypan blue. The infected root-pieces were examined under dissecting microscope at 10-40 X magnification.

\section{Assessment of root colonization}

For assessment of root colonization, the slide method proposed by Giovannetti and Mosse (1998) was followed. The root-pieces ( $1 \mathrm{~cm}$ long) were selected at random from the stained samples and mounted on microscopic slide in groups of 10. Presence of infection was recorded in each of the 10-pieces, and percentage infection was calculated as:

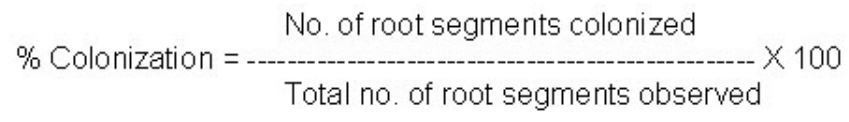

In all 20 roots were examined.

\section{Statistical analysis}

The data were statistically analyzed using general linear model ANOVA (Bailey, 1995).

\section{RESULTS AND DISCUSSION}

Piriformospora indica is a new endophyte isolated from desert soil of Rajasthan (Verma et al. 1998). The fungus enhances the growth of $A$. vasica (Figure 2) as earlier reported with $S$. calva and $W$. somnifera (Rai et al. 2001). We observed a profuse proliferation of roots of $A$. vasica after inoculation of $P$. indica (Figure 1d), which was not observed in our previous experiments (Rai et al. 2001). Root-colonization of $A$. vasica by $P$. indica increased with time from $53 \%$ after 2 months to $95 \%$ after 6 months (Figure 1e).

There was a remarkable enhancement in the growth rate of the plant inoculated with $P$. indica. The growth was very fast up to 2 months (Table 2) and slowed-down thereafter. At each observation time, growth was significantly higher for the plants inoculated with $P$. indica versus the control plants.

The fresh and dry weight of shoots and roots of $A$. vasica inoculated plants was higher than that of the corresponding controls (Table 2). This suggests that $P$. indica is a suitable endophyte for fast growth of the plants. An additional benefit of $P$. indica is its ability to be cultured in artificial culture medium (Figure 1a and 1b), whereas other arbuscular mycorrhizal fungi, being obligate symbiont can not be cultured in the absence of a suitable host partner.

After additional trials and evaluation of active principles or secondary metabolites production, $P$. indica may be recommended for growth enhancement of $A$. vasica.

\section{REFERENCES}

BAILEY, N.T.J. Statistical Methods in Biology. Cambridge University Press, Cambridge, 1995, p. 251. ISBN 0-521498457.

BLECHERT, O.; KOST, G.; HASSEL, A.; REXER, R.H. and VARMA, A. First remarks on the symbiotic interactions between Piriformospora indica and terrestrial orchid. In: VARMA, A. and HOCK, B. eds. Mycorrhizae. $2^{\text {nd }}$ ed. Springer Verlag, Germany, 1999, p. 683-688.

DEY, A.C. Indian medicinal plants used in ayurvedic preparations, Bishen Singh Mahendra Pal Singh, Dehra Dun, 1980, p. 202.

FRANKEN, P.; BUETEHORN, B. and VARMA, A. Piriformospora indica, a cultivable root cell-infecting fungus promotes the growth of a broad range of plant species. In: International Congress on Mycorrhiza. $\left(2^{\circ}, 5^{\text {th }}\right.$ $9^{\text {th }}$ July, 1998, Sweden). 1998, p. 65. 
GIOVANNETTI, M. and MOSSE, B. An evaluation of techniques for measuring vesicular- arbuscular mycorrhizal infection in roots. New Phytologist, 1998, vol. 84, p. 489500 .

KAFER, E. Meiotic and mitotic recombination in Aspergillus and its chromosomal aberrations. Advances in Genetics, 1977, vol. 19, p. 33-131.

MALLA, R.; SINGH, A.; ZEYAULLAH, M.D.; YADAV, V.; VERMA, A.; VARMA, A. and RAI, M. Piriformospora indica and plant growth promoting rhizobacteria: an appraisal. In: RAO, G.P.; MANOHARACHARI, C.; BHAT, D.J.; RAJAK, R.C. and LAKHANPAL, T.N. eds. Frontiers of Fungal Diversity in India (Prof. Kamal Festscrift). International Book Distributing Co. Lucknow, India, 2002, p. 401-419.

RAI, M. and VARMA, A. Field performance of Withania somnifera Dunal after inoculation with three species of Glomus. Journal of Basic and Applied Mycology, 2002, vol.1, p. 74-80.

RAI, M.; ACHARYA, D.; SINGH, A. and VARMA, A. Positive growth responses of the medicinal plants Spilanthes calva and Withania somnifera to inoculation by Piriformospora indica in a field trial. Mycorrhiza, 2001, vol. 11, p. 123-128.

SINGH, A.; SHARMA, J.; REXER, K.H. and VARMA, A. Plant productivity determinants beyond minerals, water and light. Piriformospora indica: a revolutionary plant growth promoting fungus. Current Science, 2000, vol.79, p. 101106.

SINGH, V. and JAIN, D.K. Taxonomy of angiosperms, Rastogi publications, Meerut, 1987, p. 1-564.

VARMA, A.; SINGH, A.; SUDHA, S.; SHARMA, J.; ROY, A.; KUMARI, M.; RANA, D.; THAKRAN, S.; DEKA, D.; BHARTI, K.; HUREK, T.; BLECHERT, O.; REXER, K.H.; KOST, G.; HAHN, A.; MAIER, W.; WALTER, M.; STRACK, D. and KRANNER, I. Piriformospora indica-an axenically culturable mycorrhizalike endosymbiotic fungus. In: HOCK, B. ed. Mycota IX. Springer, Berlin, Heidelberg, New York, 2001, p. 123-150.

VARMA, A.; SUDHA, S. and FRANKEN, P. Piriformospora indica-a cultivable plant growth promoting root endophyte with similarities to arbuscular mycorrhizal fungi. Applied and Environmental Microbiology, 1999, vol. 65 , p. $2741-2744$.

VERMA, S.; VARMA, A.; REXER, K.H.; KOST, G.; SARBHOY, A.; BISEN, P.; BUTEHORN, B. and FRANKEN, P. Piriformospora indica, gen. et sp. nov., a new root-colonizing fungus. Mycologia, 1998, vol. 95, p. 896-903. 


\section{APPENDIX}

\section{Tables}

Table 1. \% colonization of roots of Adhatoda vasica after inoculation of $P$. indica.

\begin{tabular}{|l|c|c|c|c|c|}
\hline \multirow{2}{*}{ Treatment } & \multicolumn{5}{|c|}{ Duration of growth of Adhatoda vasica (month wise) } \\
\cline { 2 - 6 } & 2 & 3 & 4 & 5 & 6 \\
\hline Control & - & - & - & - & - \\
\hline P. indica & $54( \pm 1.4)$ & $72( \pm 1.4)$ & $82( \pm 1.2)$ & $88( \pm 1.2)$ & $95( \pm 0.9)$ \\
\hline
\end{tabular}

All values are means \pm S.D. Mean values are significantly different at $P<0.05$. No. of replicates 20 .

Table 2. Growth response of Adhatoda vasica (in $\mathrm{cm}$ ) after inoculation with Piriformospora indica.

\begin{tabular}{|l|r|r|r|r|r|}
\hline \multicolumn{1}{|c|}{ Treatment } & 2 month & 3 month & 4 month & 5 month & 6 month \\
\hline Control & $9( \pm 0.2)$ & $12( \pm 0.3)$ & $15.1( \pm 0.3)$ & $18.2( \pm 0.4)$ & $20.8( \pm 0.2)$ \\
\hline P. indica & $18( \pm 0.4)$ & $20.4( \pm 0.2)$ & $23.1( \pm 0.4)$ & $24( \pm 0.3)$ & $25.3( \pm 0.2)$ \\
\hline
\end{tabular}

All values are means \pm S.D. Mean values are significantly different at $P<0.05$. No. of replicates 20 .

Table 3. Fresh and dry weight of $A$. vasica after 6 months.

\begin{tabular}{|l|c|c|c|c|}
\hline \multirow{2}{*}{ Treatment } & \multicolumn{2}{|c|}{ Fresh weight (g) } & \multicolumn{2}{c|}{ Dry weight (g) } \\
\cline { 2 - 5 } & Shoot & Root & Shoot & Root \\
\hline Control & $214( \pm 1.1)$ & $172( \pm 1.4)$ & $66( \pm 1)$ & $35( \pm 0.6)$ \\
\hline P. indica & $465( \pm 1.2)$ & $400( \pm 1.9)$ & $159( \pm 1)$ & $151( \pm 1.2)$ \\
\hline
\end{tabular}

All values are means \pm S.D. Mean values are significantly different at $P<0.05$.

No. of replicates 20 . 
Figures

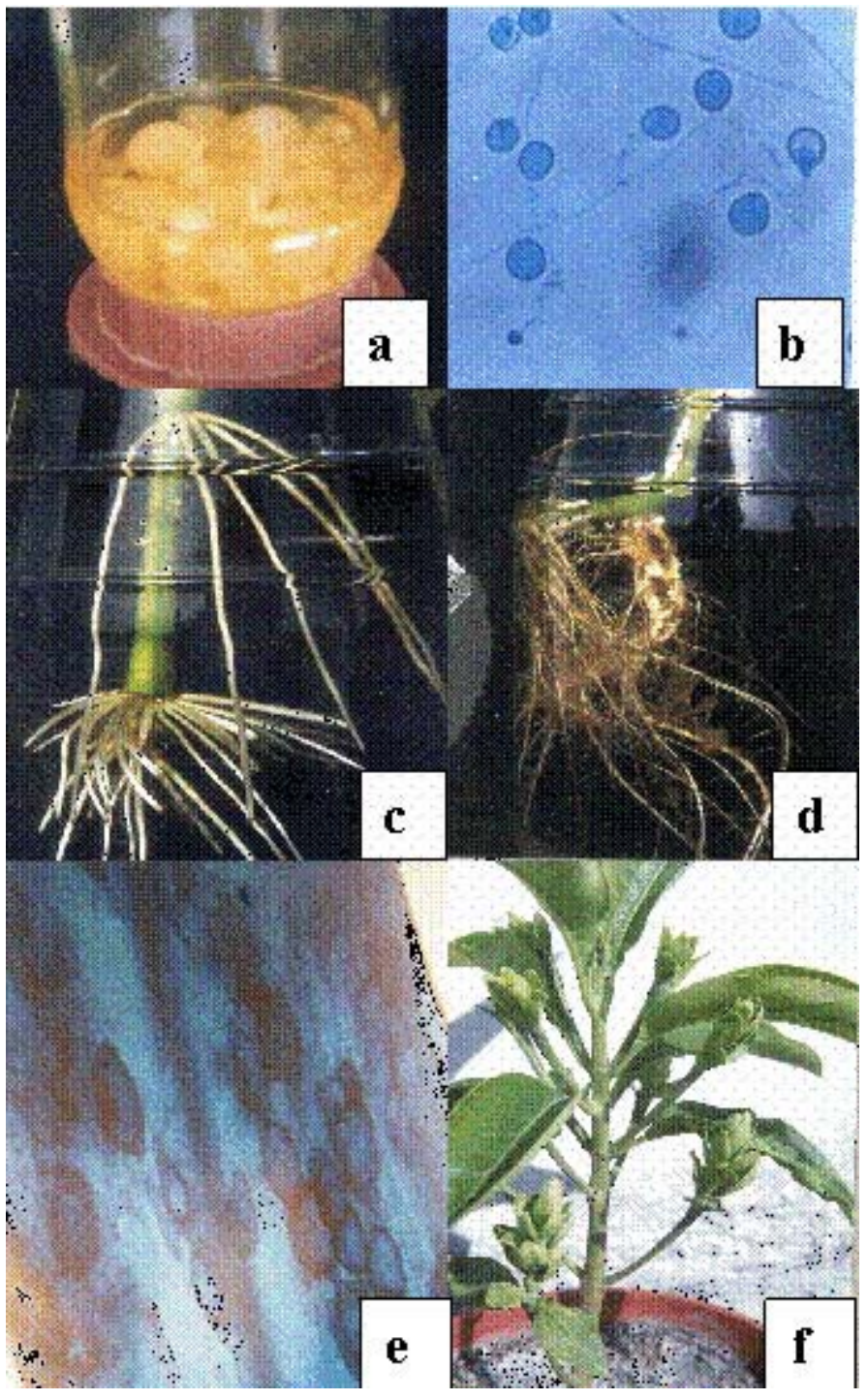

Figure 1.

(a) Culture of Piriformospora indica.

(b) Spores of $P$. indica.

(c) Adhatoda vasica roots.

(d) A. vasica after inoculation.

(e) Chlamydospores of $P$. indica in roots.

(f) $P$. indica inoculated plant of $A$. vasica. 
Rai, M. and Varma, A.

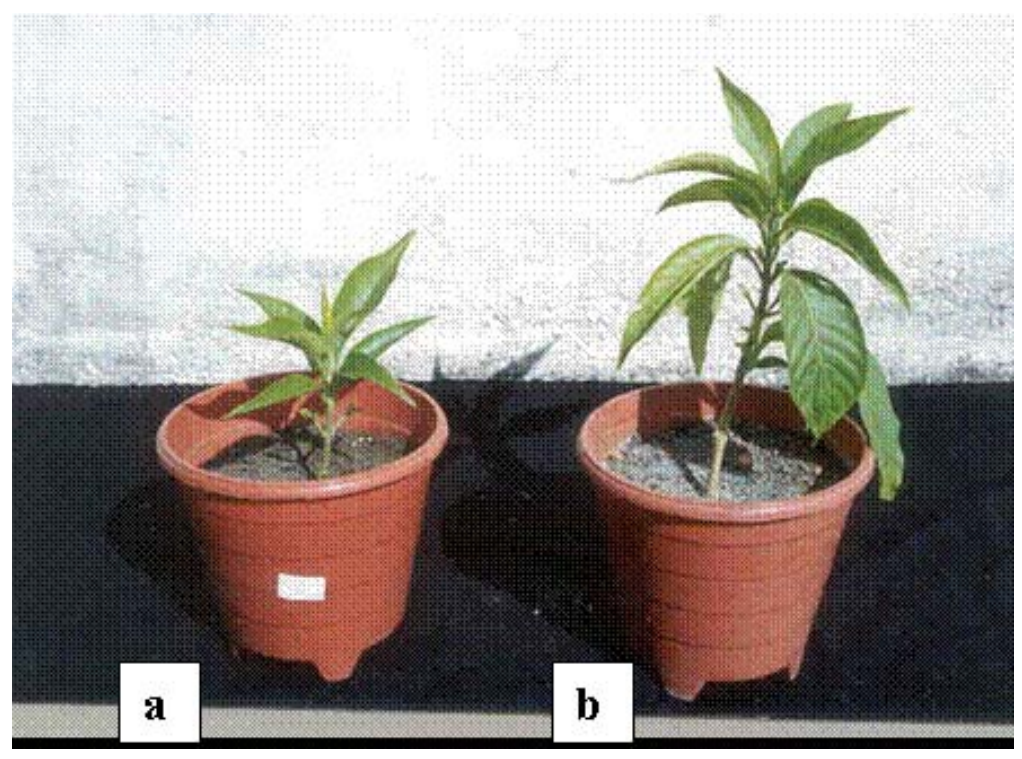

Figure 2. Adhatoda vasica

(a) Control.

(b) Inoculated with $P$. Indica. 